\title{
ESTUDO COMPARATIVO NO EMPREGO DOS FATORES DE RESPOSTA DO ANALISADOR DE HIDROCARBONETOS, SEGUNDO A NORMA ABNT NBR 6601, VERSÕES 2005 E 2012
}

\author{
Raphael Bellis de Sousa ${ }^{1}$, Vanderlei Rodrigues Ferreira ${ }^{1}$, Rui de Abrantes ${ }^{1}$ e Vanderlei \\ Borsari $^{1}$ \\ ${ }^{1}$ CETESB - Companhia Ambiental do Estado de São Paulo
}

E-mails: bellischemistry@gmail.com, vrferreira@sp.gov.br, ruiabnt@gmail.com e vborsari@sp.gov.br

\section{RESUMO}

A norma ABNT NBR 6601:2012, vigente desde 18 de outubro de 2012, padronizou o conceito e emprego dos fatores de resposta de etanol e metano do analisador de hidrocarbonetos que utiliza o Detector de Ionização de Chama, DIC (Flame Ionization Detector - FID). Este trabalho faz um levantamento histórico relativo à metodologia de cálculo e valores dos fatores de resposta na área de emissão veicular brasileira permitindo compreender melhor os conceitos envolvidos em todos os ensaios de veículos leves com os diversos tipos de combustíveis descritos pela Norma ABNT NBR 8689:2012, tanto em ensaios de emissão evaporativa (com exceção de veículos abastecidos com GNV ou diesel) quanto de emissão de escapamento. Também foi possível verificar que a introdução do conceito do fator de resposta de metano do DIC, $\mathrm{Fr}_{\mathrm{CH}_{4}}$, na metodologia de cálculo de ensaios de emissão de veículos leves abastecidos com gasolina, suas misturas com etanol, gás natural veicular (GNV) e diesel não gera mudanças significativas nos resultados referentes aos NMHC, enquanto para ensaios de emissão de veículos leves abastecidos com etanol hidratado combustível há mudanças significativas nos resultados referentes aos NMHC-ETOH. Isso faz com que se estude uma possível atualização dos limites de hidrocarbonetos não metano. Os fatores de resposta de etanol do DIC, $\mathrm{Fr}_{\mathrm{ETOH}}$, e de $\mathrm{Fr}_{\mathrm{CH}_{4}}$ são relativamente próximos entre si, respectivamente, para as diferentes marcas e modelos de analisadores de hidrocarbonetos utilizados pelos Laboratórios de Emissão Veicular, LEV, em ensaios de emissão, porém, sofrem variações que interferem nos resultados gerados por estes, e, por consequência, dos cálculos que os empregam, indicando que os valores de fatores de resposta do DIC são inerentes de cada analisador. [1,2]

\section{INTRODUÇÃO}

O Programa de Controle de Poluição do Ar por Veículos Automotores, PROCONVE, e o Programa de Controle de Poluição do Ar por Motociclos e Veículos Similares, PROMOT, foram criados pelo Conselho Nacional do Meio Ambiente, CONAMA, por meio de resoluções que estabelecem diretrizes, prazos, e padrões legais de emissões admissíveis para as diferentes categorias de veículos automotores, nacionais e importados. [3] 
A criação do PROCONVE/PROMOT baseou-se na experiência internacional para adequar os índices à realidade brasileira e tem como principal meta a redução da contaminação atmosférica das fontes móveis, por meio da fixação dos limites máximos de emissão, induzindo o desenvolvimento tecnológico dos fabricantes e estabelecendo exigências tecnológicas para veículos, cuja comprovação é feita a partir de ensaios padronizados. A certificação de protótipo/projeto e o acompanhamento estatístico em veículos de produção também fazem parte da estratégia de controle. [3]

Atualmente, o PROCONVE classifica os veículos automotores em seis principais classes: Veículo Leve de Passageiros (Automóveis), Veículo Leve Comercial (Utilitários), Veículo Pesado (Ônibus e Caminhões), Veículo de Duas Rodas e Assemelhados (Motocicletas e Ciclomotores), e, Máquinas Agrícolas e Rodovias Novas, sendo que os ensaios de emissões do gás de escapamento descritos na norma ABNT NBR 6601 são aplicados às duas primeiras classificações. [3]

O controle de emissão dos veículos é escalonado em fases. Os veículos leves de passageiros, principal objeto deste estudo, por possuírem a maior porcentagem de veículos que utilizam como combustível etanol, já possuem seis fases descritas (também serão abordados, em menor grau, os veículos comerciais leves). [3]

Durante as fases L1 a L3 foram homologados veículos leves de passageiros que utilizavam como combustível gasolina, etanol (exclusivo) e GNV (veículos de passageiros a diesel são proibidos no Brasil desde 1976). [4,5,6]

Entre os objetivos propostos e alcançados das fases L1 a L3 do PROCONVE estavam: L1) Aprimoramento dos modelos já em produção e redução das tolerâncias na produção, além do início do controle da emissão evaporativa; L2) Aplicação de tecnologias novas, tais como a injeção eletrônica ou carburadores assistidos eletronicamente e os conversores catalíticos para a redução de emissões que, utilizadas separadamente, atendiam as exigências, além do começo do controle de ruído; L3) Por meio do atendimento aos limites estabelecidos a partir de $1^{\circ}$ de janeiro de 1997 , o fabricante/importador empregou, conjuntamente, as melhores tecnologias disponíveis para a formação de mistura e controle eletrônico do motor.

Como as várias classes de veículos dedicados a etanol atendiam sem grandes dificuldades os limites máximos de emissão de poluentes das fases L1 a L3 quando comparado aos veículos à gasolina, a homologação de veículos a etanol não era inviável durante este período. Apesar do exposto, o CONAMA estabeleceu diretrizes relacionadas à utilização do etanol como combustível por meio da Resolução CONAMA n 04/1989, Resolução CONAMA n ${ }^{\circ}$ 15/1989 e Resolução CONAMA n ${ }^{\circ}$ 09/1994. [7,8,9]

Analisando-se os gráficos de produção e licenciamento de veículos leves de passageiros novos por combustível entre o período de 1979 e 2011, Figuras 01 e 02, pode-se observar que os dois gráficos são muito semelhantes, ou seja, a grande maioria dos veículos leves de passageiros produzidos no Brasil alimentava o próprio mercado interno. [10] 


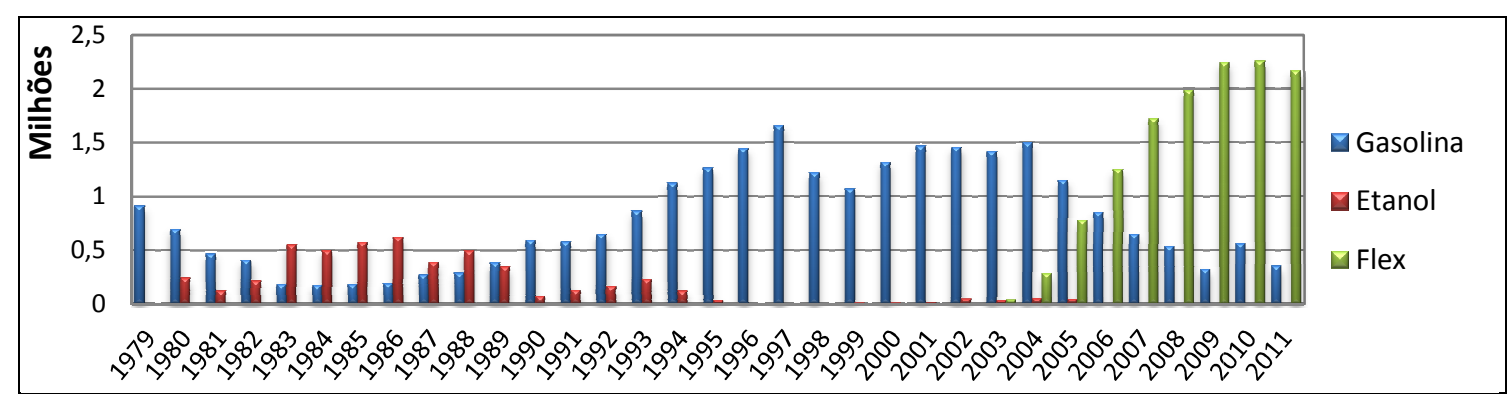

Figura 01. Produção de veículos leves de passageiros por combustível entre o período de 1979 e 2011. [10]

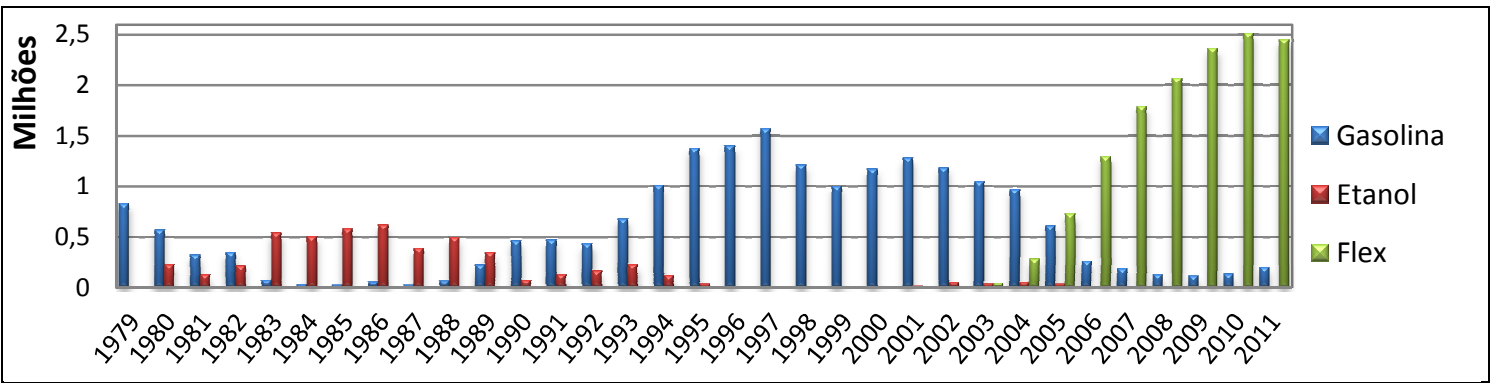

Figura 02. Licenciamento de veículos leves de passageiros novos por combustível entre o período de 1979 e 2011. [10]

Portanto, o gráfico de produção de veículos leves de passageiros pode ser utilizado para compreender indiretamente a proporção de homologação de veículos leves de passageiros, por tipo de alimentação, sabendo-se que há a tendência industrial de não acúmulo de estoque (estoque parado gera custos).

A produção dos veículos leves de passageiros dedicados a etanol, observada pelo gráfico da Figura 01, começou a apresentar uma queda em relação aos dedicados à gasolina, tomando como referência a data de $1^{\circ}$ de janeiro de 1989 (início do controle via PROCONVE de emissão de gases por veículos em território nacional), devido à crise do Pró-Álcool. Tal queda, também se reflete nas homologações por período.

Com o advento dos veículos flex ao final da fase L3, porém já próximo à fase L4, com início escalonado entre janeiro de 2005 e janeiro de 2007, cujos limites máximos de emissão de poluentes eram mais rigorosos, houve a necessidade de rediscutir a metodologia de cálculo de emissão de hidrocarbonetos não metano, NMHC, provenientes do gás de escapamento.

\section{O INÍCIO DO FATOR DE RESPOSTA NA ÁREA VEÍCULAR - EMISSÃO EVAPORATIVA}

Um dos primeiros momentos em que o fator de resposta do DIC foi empregado na área veicular foi em ensaios de emissão evaporativa de veículos abastecidos com etanol hidratado combustível, cujo trabalho desenvolvido pelo Brasil é considerado uma das bases da legislação PROCONVE e de países que utilizam combustíveis alternativos. [2]

\section{FATORES DE RESPOSTA NA EMISSÃO DE ESCAPAMENTOS}

\subsection{Definições}


Os fatores de resposta do DIC descritos na norma ABNT NBR 6601:2012, $\mathrm{Fr}_{\mathrm{CH}_{4}}$ e $\mathrm{Fr}_{\mathrm{ETOH}}$, utilizam como princípio empregar valores adquiridos em diferentes analisadores ou/e calibrados com diferentes padrões, e convertê-los de uma forma que possam ser associados com outros mensurandos, como exemplificado no caso em que se utiliza etanol hidratado (Esquema 01). [1]

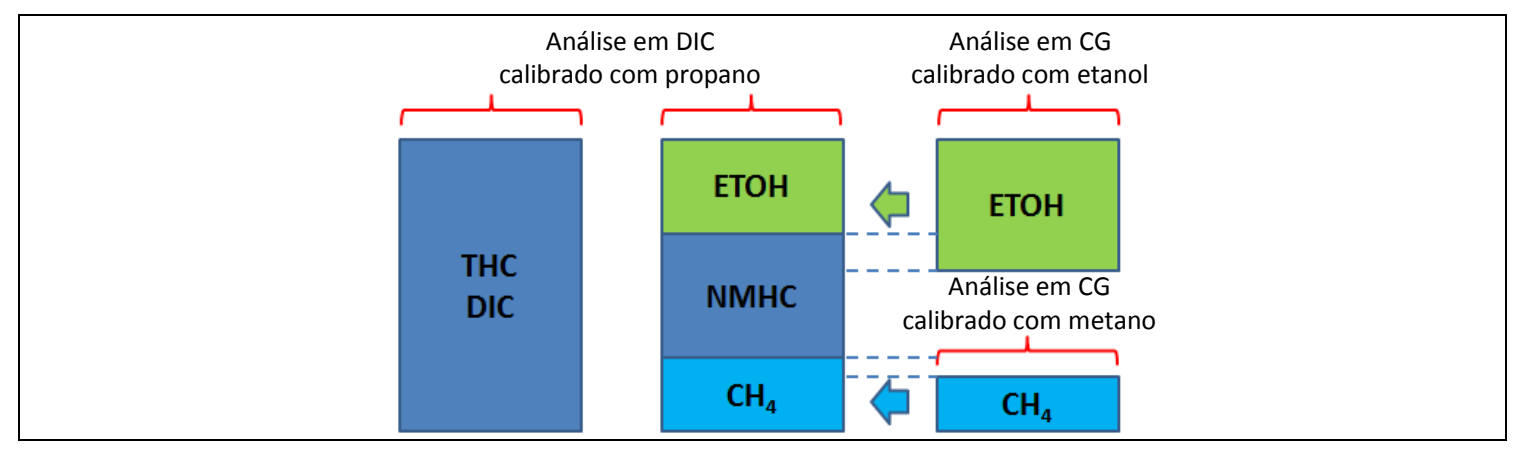

Esquema 01. Representação de como os fatores de resposta de metano e etanol do DIC são empregados no desconto dos hidrocarbonetos (fora de escala).

\subsection{Histórico}

A norma ABNT NBR 6601:2005, vigente desde 31 de outubro de 2005, definia hidrocarbonetos não metano, NMHC (non-methane hydrocabons), como os hidrocarbonetos existentes em uma amostra de gás, excluído o metano. [11]

Na norma referenciada acima, não há diferenciação entre a metodologia de cálculo de obtenção de NMHC quando se utiliza diferentes combustíveis, como gasolina, etanol, suas misturas, gás natural veicular (GNV) ou diesel. Há apenas diferenciação no cálculo de obtenção da razão de diluição, RD, entre ensaios que utilizam GNV e os demais combustíveis. [11]

$$
\mathrm{RD}=\frac{\mathrm{CO}_{2 \mathrm{ES}}}{\mathrm{CO}_{2 \mathrm{e}}+\left(\mathrm{HC}_{\mathrm{e}}+\mathrm{CO}_{\mathrm{e}}\right) \cdot 10^{-4}}
$$

Onde,

RD $\rightarrow$ Razão de diluição (adimensional);

$\mathrm{CO}_{2 \mathrm{ES}} \rightarrow$ Porcentagem teórica de $\mathrm{CO}_{2}$, dióxido de carbono, no gás resultante de uma combustão em condições estequiométricas. Para os efeitos da norma, pode ser adotado 13,4 para veículos a gasolina, etanol, suas misturas e diesel e 9,5 para veículos a GNV;

$\mathrm{CO}_{2 \mathrm{e}} \rightarrow$ Concentração de $\mathrm{CO}_{2}$ medida no balão de amostragem do gás de escapamento diluído, em porcentagem;

$\mathrm{HC}_{\mathrm{e}} \rightarrow$ Concentração de $\mathrm{HC}$, hidrocarbonetos totais, medida no balão de amostragem do gás de escapamento diluído, em ppmC; 
$\mathrm{CO}_{\mathrm{e}} \rightarrow$ Concentração de $\mathrm{CO}$, monóxido de carbono, medida no balão de amostragem do gás de escapamento diluído, em ppm.

Observação: Algumas referências adotam a abreviação THC para hidrocarbonetos totais, porém optou-se neste artigo adotar, como padronização, a sigla HC, conforme definido na norma ABNT NBR 6601:2012. [1]

A obtenção de NMHC era realizada por meio da subtração de metano dos hidrocarbonetos totais, em massa, como representado pela Equação 2:

$\mathrm{NMHC}_{\mathrm{M}}=\mathrm{HC}_{\mathrm{M}}-\mathrm{CH}_{4 \mathrm{M}}$

Onde,

$\mathrm{NMHC}_{\mathrm{M}} \rightarrow$ Emissão em massa de NMHC do gás emitido em gramas;

$\mathrm{HC}_{\mathrm{M}} \rightarrow$ Emissão em massa de $\mathrm{HC}$ em gramas;

$\mathrm{CH}_{4 \mathrm{M}} \rightarrow$ Emissão em massa de $\mathrm{CH}_{4}$ em gramas.

Portanto, era necessário calcular primeiramente as massas tanto de $\mathrm{HC}$ como de $\mathrm{CH}_{4}$, que possuem densidades diferentes, para depois realizar a subtração citada. [11]

Com a introdução dos veículos flex (veículos que podem funcionar com gasolina ou etanol hidratado combustível ou qualquer mistura desses dois combustíveis num mesmo tanque), houve a necessidade de reanálise do procedimento de cálculo referente às emissões de NMHC do gás emitidos em veículos rodoviários automotores leves. Tal ação teve como objetivo viabilizar a homologação dos veículos leves flex. [12]

Observação: Outra denominação para álcool etílico hidratado combustível é etanol hidratado combustível, sendo ambas definidas pela norma ABNT NBR 8689:2012. [13]

Apenas em 2004, por meio da Instrução Normativa IBAMA n 54/2004, permitiu-se deduzir a parcela de emissão de etanol não queimado, quando movidos a etanol hidratado - em vigor desde 22 de novembro de 2004. [14]

Observação: Os termos álcool não queimado ou etanol não queimado são utilizados apenas em textos que fazem referência a este, pois está em desuso, sendo substituído apenas pela expressão álcool ou etanol.

Apesar da Instrução Normativa IBAMA n 54/2004 não especificar como o desconto de etanol não queimado deveria ser realizado, ela condicionava esse desconto a um procedimento aprovado pelo IBAMA e/ou seu agente técnico conveniado (CETESB). [14]

Com o objetivo de padronização da metodologia do desconto de etanol não queimado do NMHC, este assunto foi levado à discussão pela Comissão Técnica de Acreditação de Laboratório de Emissões, cujo desfecho, está registrado na Ata da 
88a Reunião da Comissão Técnica de Acreditação de Laboratórios de Emissões. [15] O primeiro parágrafo do item 3.2.1 desta ata descreve esse desfecho de forma clara:

"Esta Comissão reavaliou o procedimento de cálculo da emissão final de $\mathrm{HC}$, descontando-se o etanol não queimado (ETOH) do NMHC e decidiu que a subtração dos valores de CH4 e ETOH deverá ser realizada utilizando-se os valores de concentração e não de massa, como é feito atualmente." [15]

Em outras palavras, a partir desta reunião, que ocorreu em 07 de dezembro de 2006, padronizou-se o desconto de etanol do NMHC para veículos alimentados com etanol hidratado combustível. [15] Tal fato é considerado de grande importância, pois representantes de todos os laboratórios de emissão veicular do país estavam presentes ou receberam cópias desta ata direta ou indiretamente. [16]

As novidades deste procedimento foram o desconto de etanol do NMHC por concentração e a introdução do conceito do fator de resposta do etanol do DIC, que são descritos pelas equações abaixo (alguns termos foram adaptados para melhor compreensão e entendimento): [15]

$\mathrm{ETOH}_{\text {corr e } \mid \mathrm{d}}[\mathrm{ppmC}]=2 \times \mathrm{Fr}_{\mathrm{ETOH}} \times \mathrm{ETOH}_{\mathrm{e} \mid \mathrm{d}}[\mathrm{ppmC2}]$

(Equação 03)

Onde,

$\mathrm{ETOH}_{\mathrm{e} \mid \mathrm{d}}[\mathrm{ppmC}] \rightarrow$ Emissão em concentração de ETOH de gás em [ppmC];

$\mathrm{Fr}_{\mathrm{ETOH}} \rightarrow$ Fator de resposta para medição de etanol do DIC calibrado com propano;

$\mathrm{ETOH}_{\mathrm{e} \mid \mathrm{d}}[\mathrm{ppmC2}] \rightarrow$ Emissão em concentração de ETOH de gás em [ppmC2];

e $\rightarrow$ Subscrito referente à emissão do gás de escapamento diluído de um determinado componente;

$\mathrm{d} \rightarrow$ Subscrito referente à emissão do ar de diluição de um determinado componente.

$(\mathrm{NMHC}-\mathrm{ETOH})_{e \mid d}=\mathrm{HC}_{e \mid d}-\mathrm{CH}_{4 \mathrm{e} \mid \mathrm{d}}-\mathrm{ETOH}_{\text {corr e } \mid \mathrm{d}}$

Onde,

$(\mathrm{NMHC}-\mathrm{ETOH})_{\mathrm{e} \mid \mathrm{d}} \rightarrow$ Emissão em concentração de (NMHC - ETOH) de gás em [ppmC];

$\mathrm{HC}_{\mathrm{e} \mid \mathrm{d}} \rightarrow$ Emissão em concentração de $\mathrm{HC}$ de gás em [ppmC];

$\mathrm{CH}_{4 \mathrm{e} \mid \mathrm{d}} \rightarrow$ Emissão em concentração de $\mathrm{CH}_{4}$ de gás em [ppmC];

$\mathrm{ETOH}_{\text {corr e|d }} \rightarrow$ Emissão em concentração de ETOH corrigido pelo fator de resposta de etanol do DIC de gás em [ppmC]; 
Observação: O termo NMHC-ETOH refere-se aos NMHC quando há o desconto de etanol.

Uma vez calculando os valores $(\mathrm{NMHC}-\mathrm{ETOH})_{\mathrm{e} \mid \mathrm{d}}$ para cada fase de um ensaio completo em dinamômetro de chassi, basta calcular a massa de $(\mathrm{NMHC}-\mathrm{ETOH})_{\mathrm{M}}$ em gramas, Equação 05, referente a cada uma dessas fases, e, assim, calcular a massa ponderada de $(\mathrm{NMHC}-\mathrm{ETOH})_{\mathrm{MP}}$, dada pela Equação 06. [11]

$\left(\begin{array}{c}\mathrm{NMHC} \\ -\mathrm{ETOH}\end{array}\right)_{\mathrm{M}}=\mathrm{v}_{\mathrm{ed}} \cdot \mathrm{d}_{\mathrm{HC}}\left[\left(\begin{array}{c}\mathrm{NMHC} \\ -\mathrm{ETOH}\end{array}\right)_{\mathrm{e}}-\left(\begin{array}{c}\mathrm{NMHC} \\ -\mathrm{ETOH}\end{array}\right)_{\mathrm{d}}\left(1-\frac{1}{\mathrm{RD}}\right)\right] 10^{-6} \quad$ (Equação 05)

Onde,

$(\mathrm{NMHC}-\mathrm{ETOH})_{\mathrm{M}} \rightarrow$ Emissão em massa de $(\mathrm{NMHC}-\mathrm{ETOH})$ do gás emitido, em [g];

$\mathrm{v}_{\text {ed }} \rightarrow$ Volume de gás amostrado nas condições de entrada do AVC, corrigido para a condição-padrão de temperatura e pressão $(293,15 \mathrm{~K}$ e $101,325 \mathrm{kPa})$, em [m³];

$\mathrm{d}_{\mathrm{HC}} \rightarrow$ Densidade de massa dos hidrocarbonetos igual a $576,8 \mathrm{~g} / \mathrm{m} 3$. Assumindo-se uma relação carbono-hidrogênio média de 1:1,85 a 293,15 K e 101,325 kPa.

$\left(\begin{array}{c}\mathrm{NMHC} \\ -\mathrm{ETOH}\end{array}\right)_{\mathrm{MP}}=0,43\left(\frac{\left(\begin{array}{c}\mathrm{NMHC} \\ -\mathrm{ETOH}\end{array}\right)_{\mathrm{TF}}+\left(\begin{array}{c}\mathrm{NMHC} \\ -\mathrm{ETOH}\end{array}\right)_{\mathrm{E}}}{\mathrm{D}_{\mathrm{TF}}+\mathrm{D}_{\mathrm{E}}}\right)+0,57\left(\frac{\left(\begin{array}{c}\mathrm{NMHC} \\ -\mathrm{ETOH}\end{array}\right)_{\mathrm{TQ}}+\left(\begin{array}{c}\mathrm{NMHC} \\ -\mathrm{ETOH}\end{array}\right)_{\mathrm{E}}}{\mathrm{D}_{\mathrm{TQ}}+\mathrm{D}_{\mathrm{E}}}\right)$

Onde,

$(\mathrm{NMHC}-\mathrm{ETOH})_{\mathrm{MP}} \rightarrow$ Emissão ponderada de (NMHC - ETOH) do gás emitido, em $[\mathrm{g} / \mathrm{km}]$

$(\mathrm{NMHC}-\mathrm{ETOH}) \rightarrow$ Emissão em massa de (NMHC - ETOH) do gás emitido em uma dada fase do ciclo, em [g], com exceção do subscrito "MP";

$\mathrm{D} \rightarrow$ Distância percorrida pelo veículo, medida durante uma dada fase do cilo, em [km], com exceção do subscrito "MP";

${ }_{\mathrm{TF}} \rightarrow$ Subscrito referente à fase transitória com partida a frio;

$\mathrm{E} \rightarrow$ Subscrito referente à fase estabilizada;

$\mathrm{TQ} \rightarrow$ Subscrito referente à fase transitório com partida a quente.

Apenas em 2012, com a publicação da norma ABNT NBR 6601:2012, vigente desde 18 de outubro de 2012, houve a citação da metodologia de desconto de etanol por meio de normatização, incluindo o conceito de fator de resposta de metano do DIC, por meio da Equação 07: [1]

$\left(\begin{array}{c}\mathrm{NMHC} \\ -\mathrm{ETOH}\end{array}\right)_{\mathrm{M}}=\mathrm{v}_{\mathrm{ed}} \cdot \mathrm{d}_{\mathrm{HC}}\left\{\mathrm{HC}-\mathrm{CH}_{4 \mathrm{corr}}-\mathrm{ETOH}_{\mathrm{corr}}\right\} 10^{-6}$

(Equação 07) 
Onde,

$\mathrm{HC}=\mathrm{HC}_{\mathrm{e}}-\mathrm{HC}_{\mathrm{d}}\left(1-\frac{1}{\mathrm{RD}}\right) \rightarrow$ Emissão em concentração de $\mathrm{HC}$ de gás, já descontado a parcela referente ao ar de diluição, em [ppmC];

$\mathrm{CH}_{4 \text { corr }}=\mathrm{Fr}_{\mathrm{CH}_{4}}\left[\mathrm{CH}_{4}-\mathrm{CH}_{4}\left(1-\frac{1}{\mathrm{RD}}\right)\right] \rightarrow$ Emissão em concentração de $\mathrm{CH}_{4}$ corrigido pelo respectivo fator de resposta do DIC de gás, já descontado a parcela referente ao ar de diluição, em [ppmC];

$\mathrm{Fr}_{\mathrm{CH}_{4}} \rightarrow$ Fator de resposta para medição de metano do DIC calibrado com propano;

$\mathrm{ETOH}_{\text {corr }}=\mathrm{ETOH}_{\mathrm{e}}-\mathrm{ETOH}_{\mathrm{d}}\left(1-\frac{1}{\mathrm{RD}}\right) \rightarrow$ Emissão em concentração de ETOH corrigido pelo respectivo fator de resposta do DIC de gás, já descontado a parcela referente ao ar de diluição, em [ppmC].

É importante destacar que o conceito de $\mathrm{Fr}_{\mathrm{CH}_{4}}$ também foi incorporado ao cálculo de NMHC com a norma ABNT NBR 6601:2012, quando não se utiliza etanol hidratado combustível durante o ensaio como descrito pela Equação 08: [1]

$\mathrm{NMHC}_{\mathrm{M}}=\mathrm{v}_{\mathrm{ed}} \cdot \mathrm{d}_{\mathrm{HC}}\left\{\mathrm{HC}-\mathrm{CH}_{4 \mathrm{corr}}\right\} 10^{-6}$

(Equação 08)

2.3. Estudo comparativo

\subsubsection{Ensaios que não utilizam etanol hidratado combustível}

Realizando, em um primeiro momento, uma breve comparação entre os procedimentos descritos pelas normas ABNT NBR 6601 versões 2005 e 2012, no que se refere ao cálculo de NMHC quando se utiliza como combustível gasolina, suas misturas com etanol, GNV e diesel, percebe-se que há grandes diferenças em relação aos conceitos adotados. [11,1]

$\mathrm{Na}$ versão 2005, a metodologia de cálculo utiliza uma subtração de metano de hidrocarbonetos totais em termos de massa, enquanto a versão 2012 utiliza essa mesma subtração em termos de concentração já incorporando o fator de resposta do metano do DIC. [11,1]

O primeiro passo para avaliar as diferenças de metodologia citadas é expandindo a Equação 02 em termos de seus componentes de massa: [11]

$$
\begin{aligned}
\text { NMHC }_{M}= & \left\{\mathrm{v}_{\mathrm{ed}} \cdot \mathrm{d}_{\mathrm{HC}}\left[\mathrm{HC}_{\mathrm{e}}-\mathrm{HC}_{\mathrm{d}}\left(1-\frac{1}{\mathrm{Rd}}\right)\right] 10^{-6}\right\} \\
& -\left\{\mathrm{v}_{\mathrm{ed}} \cdot \mathrm{d}_{\mathrm{CH} 4}\left[\mathrm{CH}_{4 \mathrm{e}}-\mathrm{CH}_{4 \mathrm{~d}}\left(1-\frac{1}{\mathrm{Rd}}\right)\right] 10^{-6}\right\}
\end{aligned}
$$

Onde,

$\mathrm{d}_{\mathrm{CH}_{4}} \rightarrow$ Densidade de massa do metano igual a $667,1 \mathrm{~g} / \mathrm{m}^{3}$. Assumindo-se uma relação carbono-hidrogênio média de 1:1,85 a 293,15 K e 101,325 kPa. 
E substituir o termo referente à densidade do metano pela expressão dada em termos da constante $\mathrm{R}$, cuja definição é apresentada pela Equação 09, e da densidade dos hidrocarbonetos, conforme descrito pela Equação 10: [11]

$$
\begin{aligned}
& \mathrm{R}=\frac{\mathrm{d}_{\mathrm{CH} 4}}{\mathrm{~d}_{\mathrm{HC}}} \cong 1,1566 \\
& \mathrm{~d}_{\mathrm{CH} 4}=\mathrm{R} \cdot \mathrm{d}_{\mathrm{HC}}
\end{aligned}
$$

A substituição descrita no parágrafo anterior origina a Equação 11: [11]

$$
\begin{aligned}
\mathrm{NMHC}_{\mathrm{M}}= & \left\{\mathrm{v}_{\mathrm{ed}} \cdot \mathrm{d}_{\mathrm{HC}}\left[\mathrm{HC}_{\mathrm{e}}-\mathrm{HC}_{\mathrm{d}}\left(1-\frac{1}{\mathrm{Rd}}\right)\right] 10^{-6}\right\} \\
& -\left\{\mathrm{v}_{\mathrm{ed}} \cdot\left(\mathrm{R} \cdot \mathrm{d}_{\mathrm{HC}}\right)\left[\mathrm{CH}_{4 \mathrm{e}}-\mathrm{CH}_{4 \mathrm{~d}}\left(1-\frac{1}{\mathrm{Rd}}\right)\right] 10^{-6}\right\}
\end{aligned}
$$

Reescrevendo a Equação 11 em termos de seus fatores comuns, $\left(v_{\text {ed }} \cdot d_{\mathrm{HC}}\right)$ e $10^{-6}$, tem-se a Equação 12: [11]

$$
\mathrm{NMHC}_{\mathrm{M}}=\mathrm{v}_{\mathrm{ed}} \cdot \mathrm{d}_{\mathrm{HC}}\left\{\mathrm{HC}_{\mathrm{e}}-\mathrm{HC}_{\mathrm{d}}\left(1-\frac{1}{\mathrm{Rd}}\right)-\mathrm{R}\left[\mathrm{CH}_{4 \mathrm{e}}-\mathrm{CH}_{4 \mathrm{~d}}\left(1-\frac{1}{\mathrm{Rd}}\right)\right]\right\} 10^{-6} \quad \text { (Equação 12) }
$$

Reescrevendo a Equação 08 em sua forma expandida, tem-se a Equação 13: [1]

$$
\mathrm{NMHC}_{\mathrm{M}}=\mathrm{v}_{\mathrm{ed}} \cdot \mathrm{d}_{\mathrm{HC}}\left\{\mathrm{HC}_{\mathrm{e}}-\mathrm{HC}_{\mathrm{d}}\left(1-\frac{1}{\mathrm{Rd}}\right)-\mathrm{Fr}_{\mathrm{CH}_{4}}\left[\mathrm{CH}_{4 \mathrm{e}}-\mathrm{CH}_{4 \mathrm{~d}}\left(1-\frac{1}{\mathrm{Rd}}\right)\right]\right\} 10^{-6}
$$

Comparando-se a Equação 13 com a Equação 12, pode-se observar que as duas equações são muito similares, diferenciando apenas em relação aos termos $\mathrm{Fr}_{\mathrm{CH}_{4}}$ e R. [11,1]

Em outras palavras, quanto mais próximo for os valores de $\mathrm{Fr}_{\mathrm{CH}_{4}}$ e R, menores serão os efeitos da alteração de metodologia de cálculo entre as versões 2005 e 2012 da norma ABNT NBR 6601, podendo-se encontrar três situações (Tabela 01): [11,1]

Tabela 01. Comparações entre as metodologias de cálculo de $\mathrm{NMHC}_{\mathrm{M}}$ presentes nas versões 2005 e 20012 da norma ABNT NBR 6601.

\begin{tabular}{ccc}
\hline $\mathbf{F r}_{\mathbf{C H}_{4}} \cong \mathbf{R}$ & $\mathbf{F r}_{\mathbf{C H}_{4}} \ll \mathbf{R}$ & $\mathbf{F r}_{\mathbf{C H}_{4}} \gg \mathbf{R}$ \\
\hline $\mathrm{NMHC}_{\mathrm{M}(2012)} \cong \mathrm{NMHC}_{\mathrm{M}(2005)}$ & $\mathrm{NMHC}_{\mathrm{M}(2012)} \gg \mathrm{NMHC} \mathrm{M}_{\mathrm{M}(2005)}$ & $\mathrm{NMHC}_{\mathrm{M}(2012)} \ll \mathrm{NMHC}_{\mathrm{M}(2005)}$ \\
\hline Obs.: Os subscritos 2005 e 2012 referem-se aos anos das versões da norma referenciada.
\end{tabular}

$\mathrm{Na}$ análise crítica realizada pela CETESB dos processos de veículos flex homologados entre os anos de 2010 e 2011 e dados da literatura, foi possível observar visualmente que os valores de $\mathrm{Fr}_{\mathrm{CH}_{4}}$ dos Laboratórios de Emissão Veicular, LEV, são muito próximos, como representado pela Figura 03 - A. [17] 


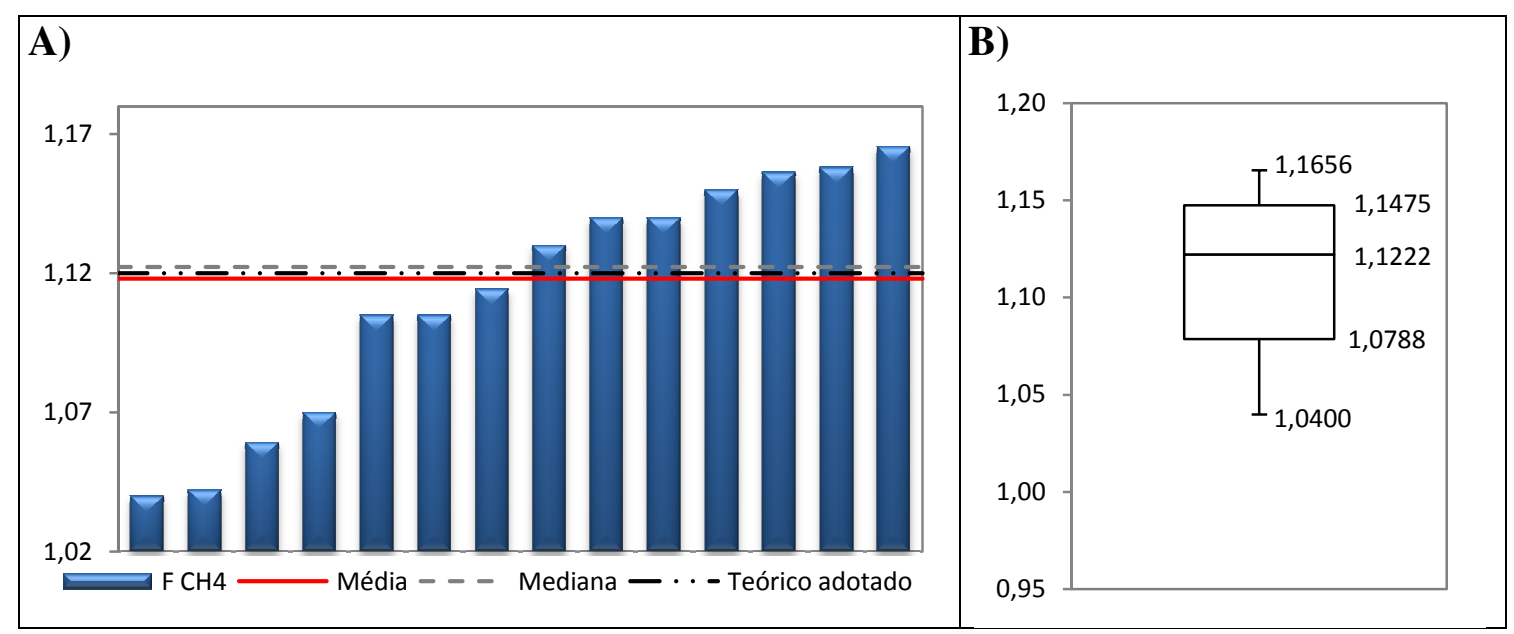

Figura 03. A) Valores de para alguns analisadores dos LEV; B) Diagrama de caixa dos dados de

A Figura 03 - A também evidencia que a média e mediana dos valores coletados de são muito próximas entre si, 1,1181 e 1,1222, respectivamente (diferença de aproximadamente $0,36 \%$ ). Devido ao exposto, o valor de de 1,12 pode ser adotado com segurança apenas para estudos teóricos.

O diagrama de caixa, boxplot, fornecido pela Figura 03 - B permite afirmar que nenhum dos dados apresentados pela Figura 3 - A foi considerado anômalo e descartado para cálculo da mediana, pois não há pontos abaixo do limite inferior $(0,9756)$ e nem acima do limite superior $(1,1819)$, representados.

Devido aos valores de serem muito próximos entre si, independente das marcas e modelos de DIC utilizados para as determinações de HC, e, estes valores também serem muito próximos do valor da constante $\mathrm{R}$ definida pela Equação 09, não há diferença significativa entre os resultados numéricos de calculados pela metodologia descrita pela norma ABNT NBR 6601 versões 2005 e 2012, para ensaios que utilizam como combustível gasolina, suas misturas com etanol, GNV e diesel. [11,1]

O exposto acima pode ser confirmado por meio dos gráficos fornecidos pelas Figuras 04 e 05, onde há a comparação das metodologias de cálculo descritas nesta seção em cerca de 900 ensaios: [17]

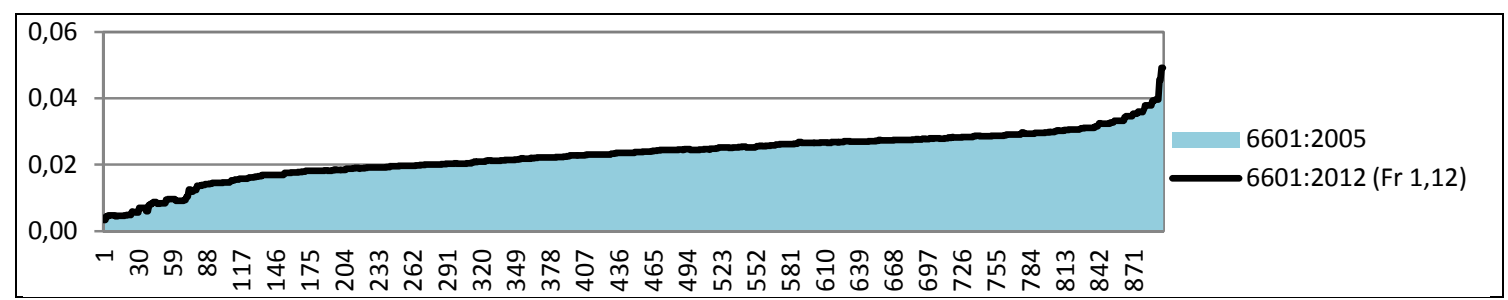

Figura 04. Gráficos comparativos entre as metodologias de cálculo de apresentadas nas versões 2005 e 2012 da norma ABNT NBR 6601 considerando

(dados dos processos de homologação de veículos flex 2010 e 2011 ensaiados com gasool A22 referência). 
Uma análise mais minuciosa dos valores fornecidos pelos gráficos da Figura 04 comprova que $94,98 \%$ dos ensaios apresentam uma diferença percentual média de apenas $0,72 \%$ (mediana de 0,70\%). Os 5,02\% restantes dos ensaios apresentam uma diferença percentual média de 13,75 \% (mediana de 13,37\%), porém estes ensaios correspondem, em sua maioria, aos menores valores de $\mathrm{NMHC}_{\mathrm{MP}}$ (como pode ser observado no início das curvas da Figura 04). Estas últimas diferenças não comprometem as homologações de veículos, pois os níveis de emissão são baixos.

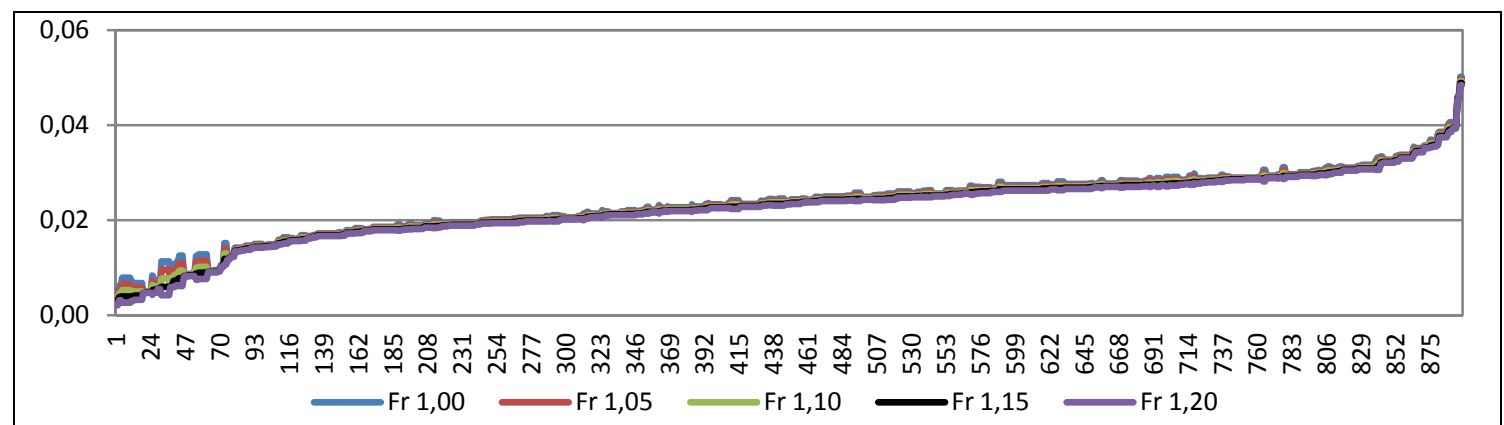

Figura 05. Gráficos comparativos entre a metodologia de cálculo de $\mathrm{NMHC}_{\mathrm{MP}}$ apresentada na norma ABNT NBR 6601:2012 variando-se os valores de $\mathrm{Fr}_{\mathrm{CH}_{4}}$ (dados dos processos de homologação de veículos flex 2010 e 2011 ensaiados com gasool A22 referência).

A Figura 05 é similar à Figura 04, porém utiliza valores de $\mathrm{Fr}_{\mathrm{CH}_{4}}$ que compreendem os valores encontrados pelos LEV (Figura 03 - A). Os mesmos 94,98 \% dos ensaios apresentam agora uma diferença percentual média de $3,84 \%$ (mediana de 3,73 \%) entre as curvas extremas (Fr igual a 1,00 e 1,20), enquanto os 5,02\% restantes dos ensaios apresentam uma diferença percentual média de 44,31\% (mediana de 43,66\%).

A grande variação citada de 44,31 \% demonstra que a determinação, verificação e utilização dos $\mathrm{Fr}_{\mathrm{CH}_{4}}$ deve ser executada com cuidado, pois é grande sua influência nos resultados dos ensaios. Consideração também válida para o $\operatorname{Fr}_{\text {ETOH }}$ (discutido na sessão 2.3.2). [2]

As curvas referentes à metodologia de cálculo apresentada pela norma $\mathrm{ABNT}$ NBR 6601:2012 são obtidas por aproximação, pois se utiliza $\mathrm{Fr}_{\mathrm{CH}_{4}}$ obtidos ao final de 2012 por cada LEV, ou seja, após um longo momento quando comparado à obtenção dos demais dados de cada ensaio (processos de homologação de veículos flex 2010 e 2011 alimentados com gasool A22 referência). Idem para a sessão 2.3.2.

$\mathrm{O}$ anunciado no parágrafo anterior é importante, pois inúmeros fatores podem afetar o $\mathrm{Fr}_{\mathrm{CH}_{4}}$, como o desgaste ou substituição de algum componente do DIC utilizado para as determinações de $\mathrm{HC}$, a utilização de um cilindro de metano diferente (pureza) ou o emprego de outra curva de calibração (calibração com propano), dentre outros. [1]

Somado às variáveis que afetam os $\mathrm{Fr}_{\mathrm{CH}_{4}}$, há outras que também afetam de diferentes modos as demais variáveis necessárias à determinação de $\mathrm{NMHC}_{\mathrm{MP}}$, 
portanto, é incorreto afirmar, apenas utilizando o valor de $\mathrm{Fr}_{\mathrm{CH}_{4}}$, que, quanto maior for o valor de $\mathrm{Fr}_{\mathrm{CH}_{4}}$ menor será o resultado de $\mathrm{NMHC}_{\mathrm{MP}}$.

\subsubsection{Ensaios que utilizam etanol hidratado combustível}

Semelhante ao exposto no item 2.3.1, uma breve comparação entre os procedimentos descritos pelas normas ABNT NBR 6601 versões 2005 e 2012 e pela Ata da 88a Reunião da Comissão Técnica de Acreditação de Laboratórios de Emissões, no que se refere ao cálculo de NMHC quando se utiliza etanol hidratado combustível, percebe-se que há grandes diferenças em relação aos conceitos adotados. [11,1,15]

Na norma ABNT NBR 6601:2005, como já descrito, a metodologia de cálculo utiliza uma subtração de metano de hidrocarbonetos totais em massa, enquanto a metodologia apresentada pela Ata da 88a aeunião da Comissão Técnica de Acreditação de Laboratórios de Emissões utiliza essa mesma subtração na grandeza de concentração já incorporando o $\mathrm{Fr}_{\mathrm{ETOH}}$. Na norma ABNT NBR 6601:2012 a metodologia é similar a descrita pela ata citada, porém também incorpora o $\mathrm{Fr}_{\mathrm{CH}_{4}} \cdot[11,1,15]$

Expandindo a Equação 05 parcialmente pela substituição da Equação 04, origina-se a Equação 14, que pode ser reescrita na forma da Equação 15: [15]

$$
\begin{aligned}
& \left(\begin{array}{c}
\mathrm{NMHC} \\
-\mathrm{ETOH}
\end{array}\right)_{\mathrm{M}}=\mathrm{v}_{\mathrm{ed}} \cdot \mathrm{d}_{\mathrm{HC}}\left[\begin{array}{c}
\left(\mathrm{HC}_{e}-\mathrm{CH}_{4 \mathrm{e}}-\mathrm{ETOH}_{\text {corr e }}\right) \\
-\left(\mathrm{HC}_{d}-\mathrm{CH}_{4 \mathrm{~d}}-\mathrm{ETOH}_{\text {corr d }}\right)\left(1-\frac{1}{\mathrm{RD}}\right)
\end{array}\right] 10^{-6} \\
& \left(\begin{array}{c}
\mathrm{NMHC} \\
-\mathrm{ETOH}
\end{array}\right)_{\mathrm{M}}=\mathrm{v}_{\mathrm{ed}} \cdot \mathrm{d}_{\mathrm{HC}}\left\{\begin{array}{c}
\mathrm{HC}_{\mathrm{e}}-\mathrm{HC}_{\mathrm{d}}\left(1-\frac{1}{\mathrm{Rd}}\right) \\
-\left[\mathrm{CH}_{4 \mathrm{e}}-\mathrm{CH}_{4 \mathrm{~d}}\left(1-\frac{1}{\mathrm{Rd}}\right)\right] \\
-\left[\mathrm{ETOH}_{\text {corr e }}-\mathrm{ETOH}_{\text {corr d }}\left(1-\frac{1}{\mathrm{Rd}}\right)\right]
\end{array}\right\} 10^{-6}
\end{aligned}
$$

Pode-se reescrever a Equação 15 substituindo os termos referentes à emissão em concentração de ETOH corrigido pelo $\mathrm{Fr}_{\mathrm{ETOH}}$ em [ppmC], pelo mesmo mensurando, porém sem a correção originada pelo fator citado, gerando a Equação 16. [15]

$$
\left(\begin{array}{c}
\mathrm{NMHC} \\
-\mathrm{ETOH}
\end{array}\right)_{\mathrm{M}}=\mathrm{v}_{\mathrm{ed}} \cdot \mathrm{d}_{\mathrm{HC}}\left\{\begin{array}{c}
\mathrm{HC}_{\mathrm{e}}-\mathrm{HC}_{\mathrm{d}}\left(1-\frac{1}{\mathrm{Rd}}\right) \\
-\left[\mathrm{CH}_{4 \mathrm{e}}-\mathrm{CH}_{4 \mathrm{~d}}\left(1-\frac{1}{\mathrm{Rd}}\right)\right] \\
-\mathrm{Fr}_{\text {Eтон }}\left[\mathrm{ETOH}_{\mathrm{e}}-\mathrm{ETOH}_{\mathrm{d}}\left(1-\frac{1}{\mathrm{Rd}}\right)\right]
\end{array}\right\} 10^{-6}
$$

A Equação 16 é muito semelhante à apresentada na norma ABNT NBR 6601:2012, Equação 17, porém a última introduz o conceito de $\mathrm{Fr}_{\mathrm{CH}_{4}}$. [15,1] 
$\left(\begin{array}{c}\mathrm{NMHC} \\ -\mathrm{ETOH}\end{array}\right)_{\mathrm{M}}=\mathrm{v}_{\mathrm{ed}} \cdot \mathrm{d}_{\mathrm{HC}}\left\{\begin{array}{c}\mathrm{HC}_{\mathrm{e}}-\mathrm{HC}_{\mathrm{d}}\left(1-\frac{1}{\mathrm{Rd}}\right) \\ -\mathrm{Fr}_{\mathrm{CH}_{4}}\left[\mathrm{CH}_{4 \mathrm{e}}-\mathrm{CH}_{4 \mathrm{~d}}\left(1-\frac{1}{\mathrm{Rd}}\right)\right] \\ -\mathrm{Fr}_{\mathrm{ETOH}}\left[\mathrm{ETOH}_{\mathrm{e}}-\mathrm{ETOH}_{\mathrm{d}}\left(1-\frac{1}{\mathrm{Rd}}\right)\right]\end{array}\right\} 10^{-6}$

(Equação 17)

Para compreender como a introdução do $\mathrm{Fr}_{\mathrm{CH}_{4}}$ afeta os resultados de (NMHC - ETOH) é necessário reescrever a Equação 17 na forma da Equação 18, que pode ser resumida na forma da Equação 19. [1]

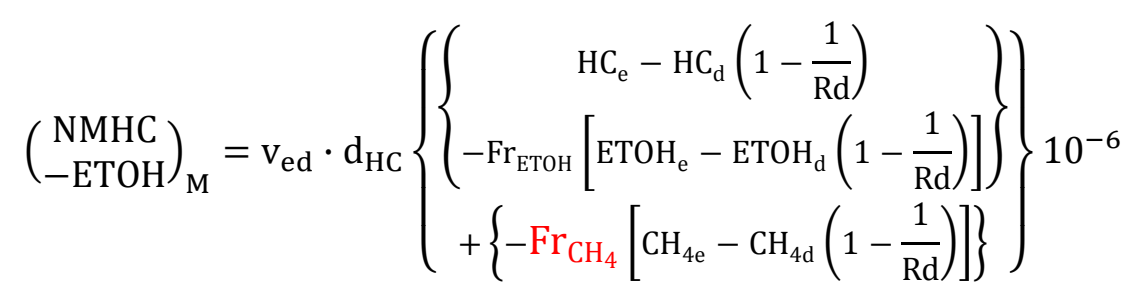

(Equação 18)

$(\mathrm{NMHC}-\mathrm{ETOH})_{\mathrm{M}}=\mathrm{v}_{\mathrm{ed}} \cdot \mathrm{d}_{\mathrm{HC}}\left\{\mathrm{A}-\mathrm{Fr}_{\mathrm{CH}_{4}} \cdot \mathrm{B}\right\} 10^{-6}$

(Equação 19)

Onde,

$A=\left\{\begin{array}{c}\mathrm{HC}_{\mathrm{e}}-\mathrm{HC}_{\mathrm{d}}\left(1-\frac{1}{\mathrm{Rd}}\right) \\ -\mathrm{Fr}_{\mathrm{ETOH}}\left[\mathrm{ETOH}_{\mathrm{e}}-\mathrm{ETOH}_{\mathrm{d}}\left(1-\frac{1}{\mathrm{Rd}}\right)\right]\end{array}\right\} \rightarrow$ Termo referente ao desconto de etanol corrigido pelo respectivo fator de resposta do DIC de gás do HC já descontado a parcela referente ao ar de diluição, em [ppmC];

$\mathrm{B}=\left[\mathrm{CH}_{4 \mathrm{e}}-\mathrm{CH}_{4 \mathrm{~d}}\left(1-\frac{1}{\mathrm{Rd}}\right)\right] \rightarrow$ Emissão em concentração de $\mathrm{CH}_{4}$ já descontado a parcela referente ao ar de diluição, em [ppmC].

A Equação 20 é a versão da Equação 19 sem a introdução do conceito do $\mathrm{Fr}_{\mathrm{CH}_{4}}$, ou seja, a metodologia de cálculo antecessora da versão 2012 da norma ABNT NBR 6601. Em outras palavras, a Equação 20 considera $\mathrm{Fr}_{\mathrm{CH}_{4}}=1,0$. [15,1]

$\left(\begin{array}{c}\mathrm{NMHC} \\ -\mathrm{ETOH}\end{array}\right)_{\mathrm{M}}=\mathrm{v}_{\mathrm{ed}} \cdot \mathrm{d}_{\mathrm{HC}}\{\mathrm{A}-1 \cdot \mathrm{B}\} 10^{-6} \equiv \mathrm{v}_{\mathrm{ed}} \cdot \mathrm{d}_{\mathrm{HC}}\{\mathrm{A}-\mathrm{B}\} 10^{-6}$

(Equação 20)

A Equação 19 é uma evidência que demonstra que a inclusão do $\mathrm{Fr}_{\mathrm{CH}_{4}}$ não afeta proporcionalmente os valores de (NMHC - ETOH) em termos de concentração, [ppmC]. Devido à propagação do resultado, os valores de (NMHC - ETOH) em termos de massa $[\mathrm{g}]$, massa por distância $[\mathrm{g} / \mathrm{km}]$ ou massa ponderada $[\mathrm{g} / \mathrm{km}]$ também não são afetados proporcionalmente pelo $\mathrm{Fr}_{\mathrm{CH}_{4}}$. [1]

Em outras palavras, um aumento de $15 \%$ no fator de resposta de metano do DIC não necessariamente aumentará em $15 \%$ os valores relacionados a qualquer grandeza de (NMHC - ETOH). [1]

Pela Equação 20 pode-se realizar a seguinte análise: Quanto maior for o valor de A em relação a B, pela metodologia antes da introdução do $\mathrm{Fr}_{\mathrm{CH}_{4}}$, maior será o 
valor de

o valor de
. Caso a subtração deve ser considerado nulo. [15]

Já com a introdução do conceito do fator de resposta de metano do DIC, representado pela Equação 19, quanto maior for o valor de , maior será o valor do termo , menor será a subtração representada por subtração , ou seja, menor será o valor - Caso a resulte em valor negativo, o valor de também deve ser considerado nulo (Tabela 2). [1]

Tabela 02. Comparações entre as metodologias de cálculo de com e sem a utilização do conceito de

$\mathrm{Na}$ análise crítica realizada pela CETESB citada no item 2.3.1 e dados da literatura, também foi possível observar que os valores de muito próximos, como representado pela Figura 06 - A. [15,17]
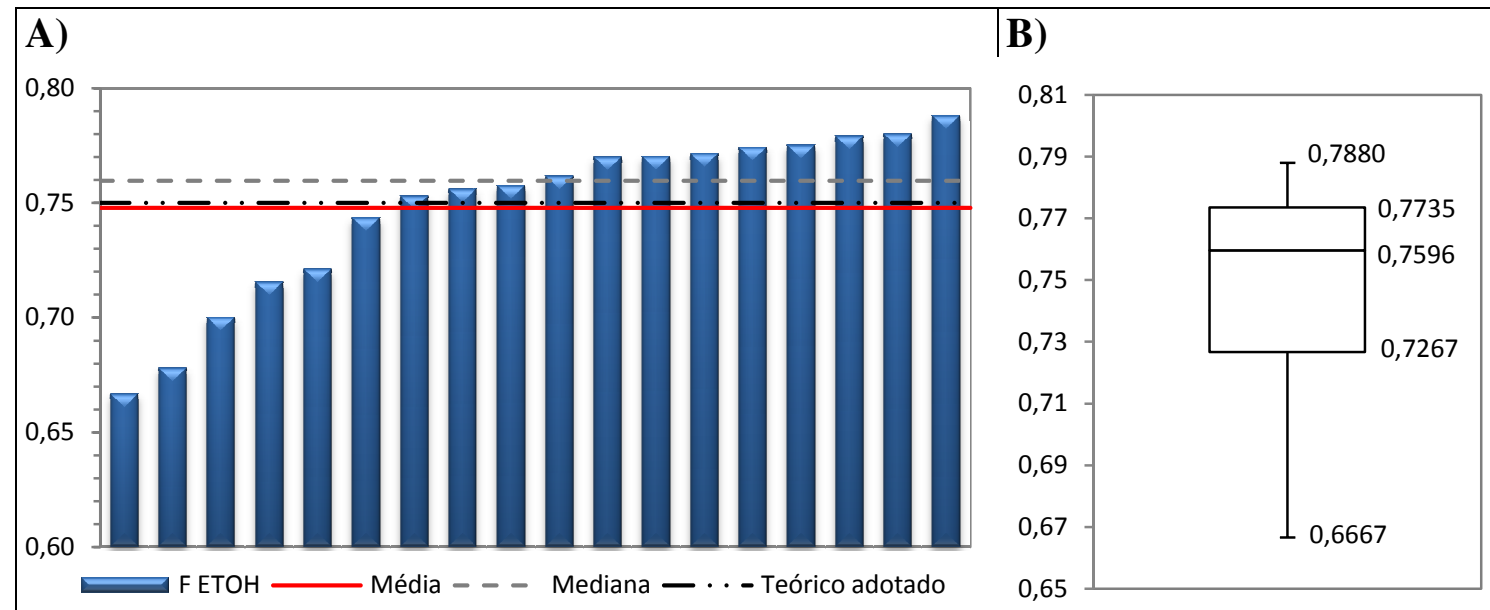

Figura 06. A) Valores de fatores de resposta para medição de etanol do DIC calibrado com propano para alguns analisadores dos LEV; B) Diagrama de caixa dos dados de

Assim como ocorre com o , a Figura 06 - A demonstra que a média e mediana dos valores coletados de são muito próximas entre si, $0,7478 \mathrm{e}$ 0,7596, respectivamente (diferença de aproximadamente $1,55 \%$ ). Devido ao exposto, o valor de de 0,75 pode ser adotado com segurança apenas para estudos teóricos.

O diagrama de caixa fornecido pela Figura 06 - B permite afirmar que nenhum dos dados apresentados pela Figura 06 - A foi considerado anômalo e descartado para cálculo da mediana (limite inferior de 0,6564 e superior de 0,7969). 
A Figura 03 - A evidencia que, para todos os casos, os valores de $\mathrm{Fr}_{\mathrm{CH}_{4}}$ são maiores do que a unidade, ou seja, há diferença significativa entre os resultados numéricos de $(\mathrm{NMHC}-\mathrm{ETOH})_{\mathrm{MP}}$ calculados pela metodologia descrita pela norma ABNT NBR 6601:2012, quando comparada à metodologia que não incluía o conceito de $\mathrm{Fr}_{\mathrm{CH}_{4}}$ para ensaios que utilizam como combustível etanol hidratado. [17,1,15]

O exposto acima pode ser confirmado por meio dos gráficos fornecidos pela Figura 07, onde há a comparação das metodologias de cálculo descritas neste subtítulo em cerca de 900 ensaios: [15,1,17]

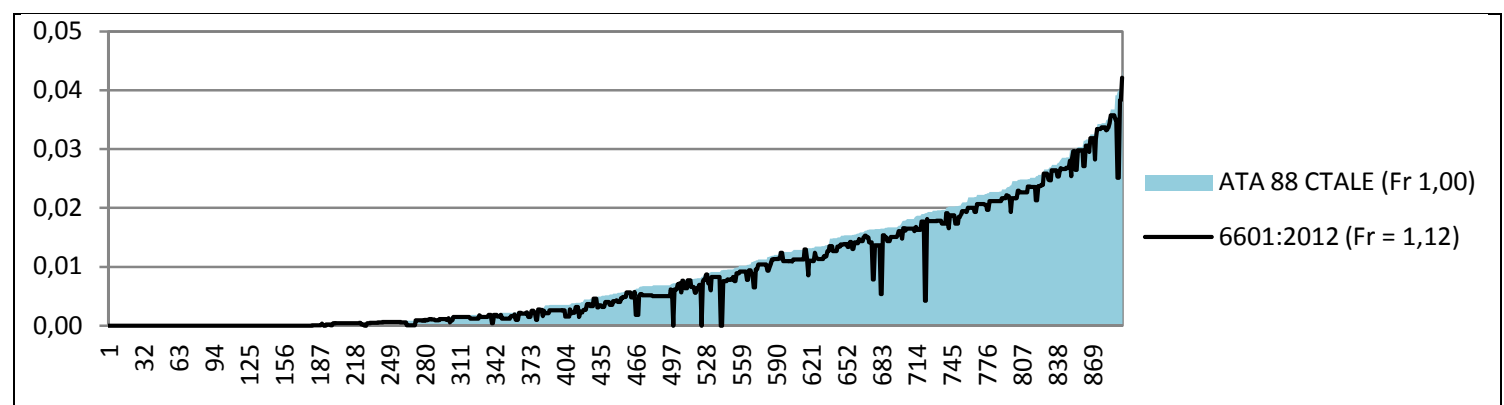

Figura 07. Gráficos comparativos de $(\mathrm{NMHC}-\mathrm{ETOH})_{\mathrm{MP}}$ adotando-se $\mathrm{Fr}_{\mathrm{CH}_{4}}=1,00$ (simulação de metodologia sem $\mathrm{Fr}_{\mathrm{CH}_{4}}$ ) e $\mathrm{Fr}_{\mathrm{CH}_{4}}=1,12$ (norma ABNT NBR 6601:2012) para dados de processos de homologação de veículos flex 2010 e 2011 ensaiados com EHR.

Uma análise simples do gráfico da Figura 07 permite observar que a maioria dos valores calculados conforme a metodologia da Ata da 88a Reunião da Comissão Técnica de Acreditação de Laboratórios de Emissões (área do gráfico - ATA 88 CTALE (Fr 1,00)) não coincidem com os valores de $(\mathrm{NMHC}-\mathrm{ETOH})_{\mathrm{MP}}$ calculados segundo a norma ABNT NBR 6601:2012 (linha preta - 6601:2012 $($ Fr 1,12$)$ ), sendo todos menores do que a metodologia anterior.

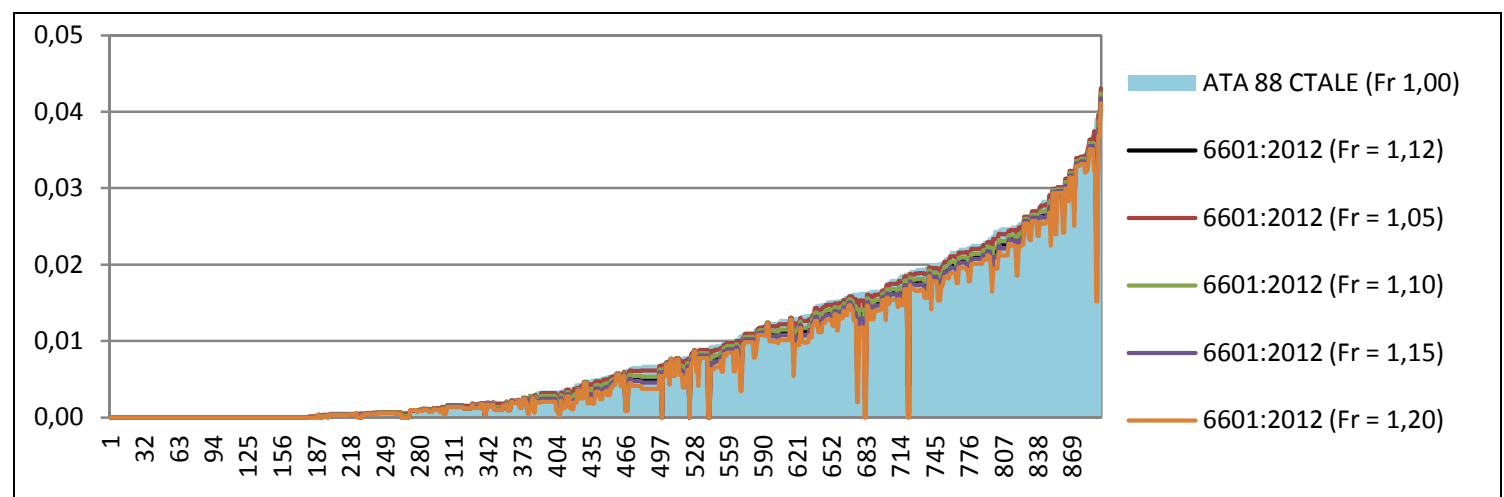

Figura 08. Gráficos comparativos entre a metodologia de cálculo de $(\mathrm{NMHC}-\mathrm{ETOH})_{\mathrm{MP}}$ apresentada na norma ABNT NBR 6601:2012 variando-se os valores de $\mathrm{Fr}_{\mathrm{CH}_{4}}$ (dados dos processos de homologação de veículos flex 2010 e 2011 ensaiados com EHR).

Os gráficos da Figura 08 mostram que quanto maior for o valor de $\mathrm{Fr}_{\mathrm{CH}_{4}}$, menores serão os resultados de $(\mathrm{NMHC}-\mathrm{ETOH})_{\mathrm{MP}}$ quando se compara a metodologia de cálculo vigente (curvas da Figura 08) com a metodologia que 
não considera o fator de resposta do metano do DIC (área - ATA 88 (CTALE $($ Fr1,00)). Estas alterações de metodologia são significativas, principalmente para altos valores de $\quad$. [1,17]

Apenas os valores dos primeiros 174 ensaios dos gráficos da Figura 07 são coincidentes, pois ambas as metodologias de cálculo ditam que caso seja encontrado algum valor negativo, este deve ser considerado nulo.

Para avaliar como a mudança de metodologia de cálculo afeta no caso dos ensaios com EHR, deve-se considerar apenas os valores que sofreram alguma alteração entre as metodologias, ou seja, os 174 casos descritos acima não serão considerados.

Agrupando-se o número de ensaios relativos aos 721 valores restantes do gráfico da Figura $07 \mathrm{em}$ intervalos de 5 unidades de porcentagem correspondentes a diferença percentual entre as metodologias analisadas, obtém-se o gráfico populacional fornecido pela Figura 09 - A e sua versão em termos de porcentagem populacional, Figura 09 - B. Deste modo, se conhece quais intervalos de diferenças percentuais contribuem mais para a mudança de metodologia.

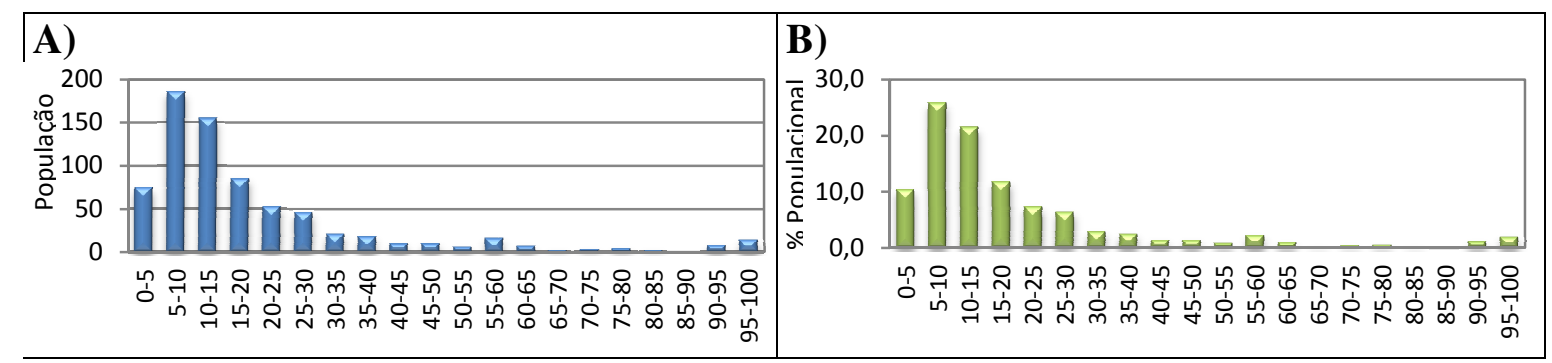

Figura 09. A) Gráfico populacional e de B) Porcentagem populacional das diferenças percentuais de ensaios entre as metodologias de cálculo de analisadas em intervalos de cinco por cento.

O gráfico da Figura 10 fornece as médias de diferenças percentuais dos ensaios dos intervalos exibidos pela Figura 09.

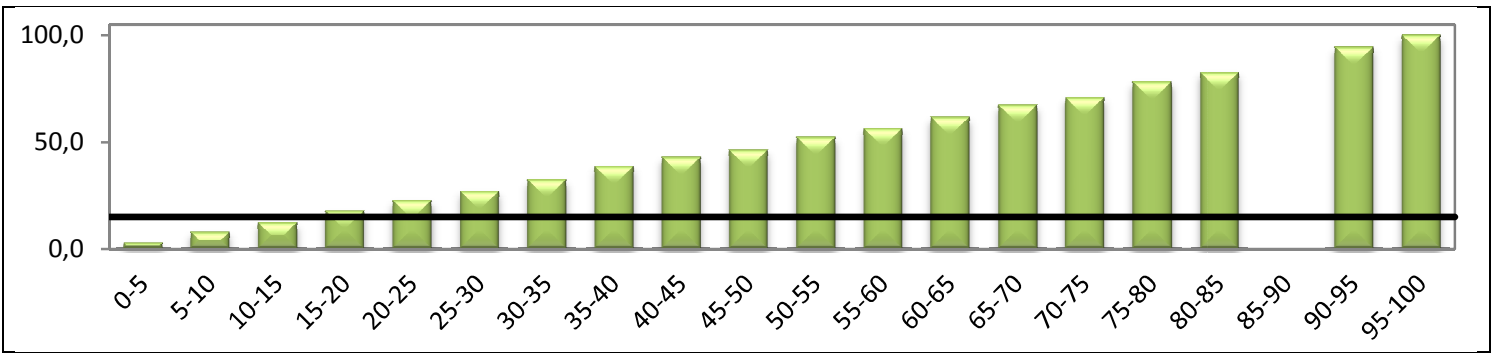

Figura 10. Gráfico das médias das diferenças percentuais de ensaios entre as metodologias de cálculo de analisadas em intervalos de cinco por cento.

A análise conjunta dos gráficos da Figura 09 - A e B permite observar que os intervalos que serão mais representativos são os compreendidos entre 5 e $20 \%$ das populações de dados (não há dados no intervalo de 85 a 90 \%). 
A média ponderada dos dados fornecidos pelas Figuras 09 e 10 comprova o descrito no parágrafo anterior, pois esta resulta em uma diferença percentual de cerca $15,00 \%$ (linha preta da Figura 10). Portanto, a mudança de metodologia de cálculo gera, via média ponderada, resultados de $(\mathrm{NMHC}-\mathrm{ETOH})_{\mathrm{MP}}$ $15,00 \%$ menores, o que representa um retrocesso no PROCONVE.

Uma alteração na metodologia de cálculo de qualquer poluente deve sempre ser acompanhada pela mudança do limite máximo de emissão do poluente definido pelo PROCONVE, quando pertinente, como é o caso dos ensaios de veículos abastecidos com EHR.

Pensando em termos do valor vigente atual de limite máximo de emissão de $(\mathrm{NMHC}-\mathrm{ETOH})_{\mathrm{MP}}$ para os veículos leves, um desconto de $15,00 \%$ não deve ser considerado pouco significativo e desprezível (Tabela 03).

Tabela 03. Limites vigentes, futuros da fase L6 e correção de limites máximos de emissão de $\mathrm{NMHC}_{\mathrm{MP}}$ de veículos leves.

\begin{tabular}{cccc}
\hline $\begin{array}{c}\text { Limites máximos de } \\
\text { emissão de NMHC }\end{array}$ & $\begin{array}{c}\text { Veículos Leves de } \\
\text { Passageiros }\end{array}$ & $\begin{array}{c}\text { Veículos Leves } \\
\text { Comerciais } \\
\mathbf{M} \leq \mathbf{1 7 0 0} \mathbf{~ k g}\end{array}$ & $\begin{array}{c}\text { Veículos Leves } \\
\text { Comerciais } \\
\mathbf{M}>\mathbf{1 7 0 0} \mathbf{~ k g}\end{array}$ \\
\hline Fase L5 (Vigente) & 0,05 & 0,05 & 0,05 \\
Fase L6 & 0,05 & 0,05 & 0,06 \\
Corrigido & 0,0425 & 0,0425 & 0,051 \\
\hline Limite corrigido & $\mathbf{0 , 0 4}$ & $\mathbf{0 , 0 4}$ & $\mathbf{0 , 0 5}$ \\
\hline
\end{tabular}

Como apenas $0,45 \%$ (quatro de 896) dos ensaios analisados com gasool A22 não atenderiam a limite corrigido de $0,04 \mathrm{~g} / \mathrm{km}$ de $\mathrm{NMHC}_{\mathrm{MP}}$ e que estes ensaios são referentes ao período de 2010 e 2011, pode-se afirmar com segurança que tanto os veículos ensaiados com gasool e EHR atenderiam uma eventual atualização de valores de limites corrigidos, propostos por este trabalho.

Quando se pensa em uma grande frota de veículos, como é o caso do Brasil, ou em casos especiais, como nos grandes centros urbanos do país, essa alteração de metodologia pode gerar elevada emissão de hidrocarbonetos não metanos.

Para o mesmo conjunto de dados utilizados na Figura 08, mas fixando-se o valor de $\mathrm{Fr}_{\mathrm{CH}_{4}}$ (valor adotado igual a 1,12), pode-se, por meio da Figura 11, observar a influência do $\mathrm{Fr}_{\mathrm{ETOH}}$ no cálculo de $(\mathrm{NMHC}-\mathrm{ETOH})_{\mathrm{M}}$. [1,17]

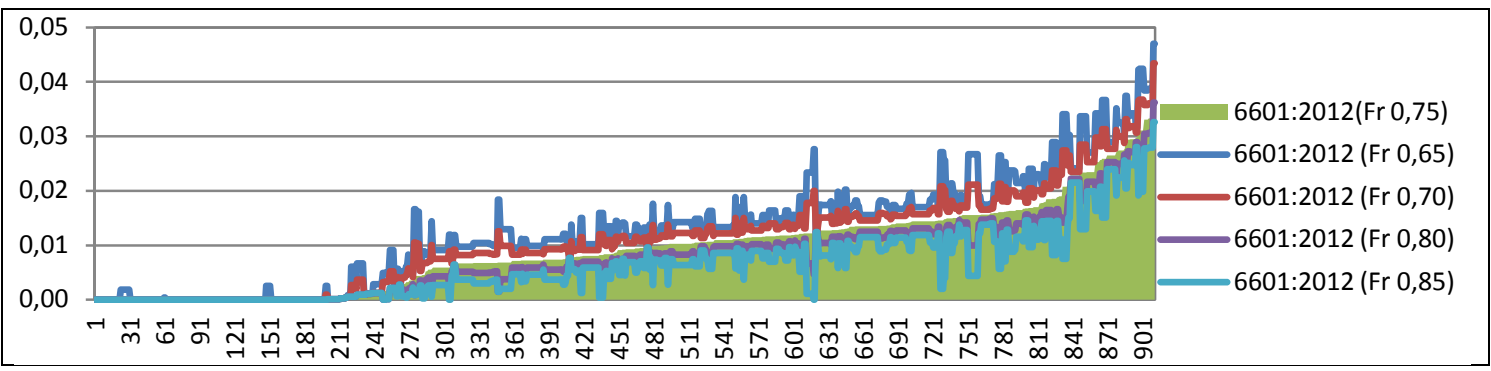

Figura 11. Gráficos comparativos entre a metodologia de cálculo vigente de $(\mathrm{NMHC}-\mathrm{ETOH})_{\mathrm{M}}$ utilizando $\mathrm{Fr}_{\mathrm{CH}_{4}}=1,12$ e variando-se o $\mathrm{Fr}_{\text {ETOH }}$ (dados dos processos de homologação de veículos flex 2010 e 2011 ensaiados com EHR). 
Como a emissão de etanol por gás de escapamento para muitos veículos tem sido alta, a utilização desta no desconto de gera valores nulos (valores negativos são considerados nulos), como exemplificados pelo intervalo de ensaios 1 a 218 da Figura 11.

A Figura 11 também pode ser utilizada para verificar que quanto maior for o valor de , menor será o valor resultante de, de mesmo modo que ocorre com o . . [1,17]

Semelhante ao , o também é afetado pela substituição de algum componente do DIC utilizado para as determinações de HC, a utilização de cilindro de etanol diferente (pureza) ou o emprego de outra curva de calibração (calibração com propano), dentre outros. [15,1]

Uma visão geral do emprego dos dois fatores de resposta de DIC discutidos pode ser observada através do exemplo da Figura 12, sendo gráficos de superfície.

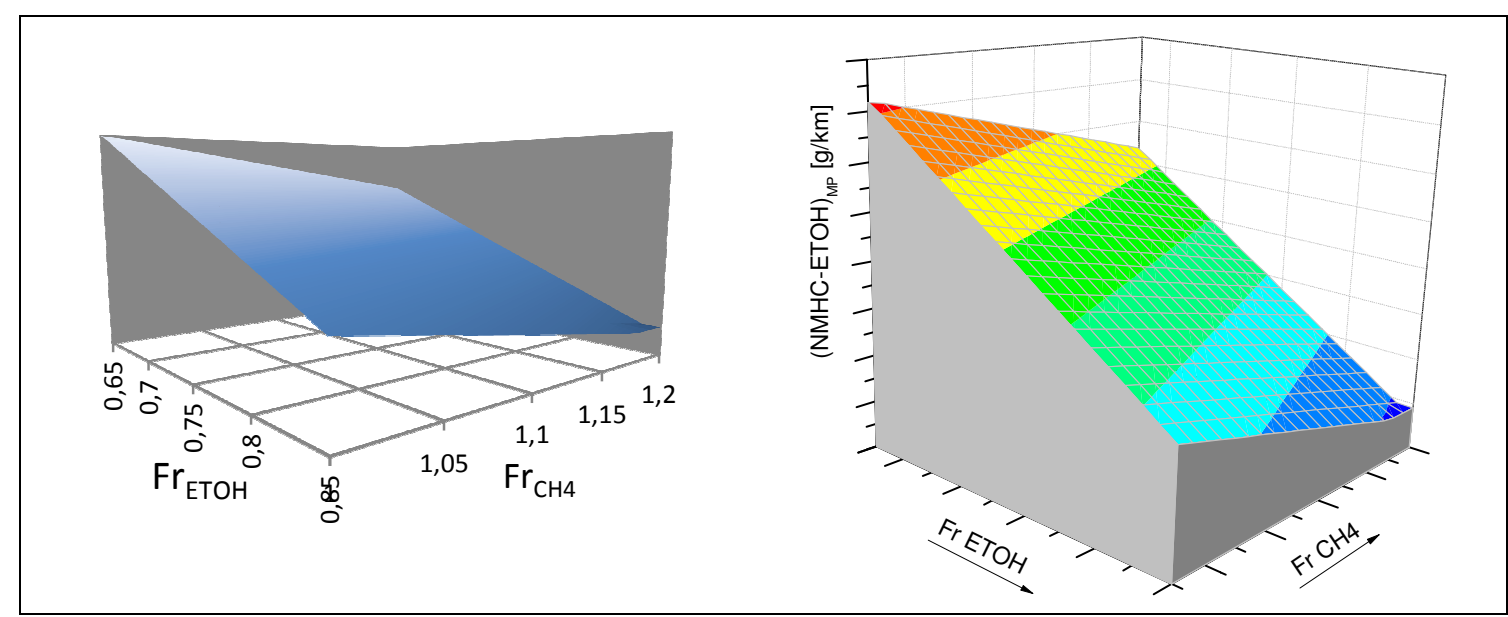

Figura 12. Gráficos de superfície de

variando-se os valores de $\mathrm{e}$ um dos ensaios com EHR dos processos de homologação de veículos flex 2010 e 2011.

Pelos gráficos da Figura 12 é possível verificar que quanto maior for os valores de e , para valores fixos das demais variáveis, menor será o valor de e os demais resultados vinculados a estes, como concentração, $[\mathrm{ppmC}]$, massa $[\mathrm{g}]$, massa por distância, $[\mathrm{g} / \mathrm{km}]$, e, massa ponderada $[\mathrm{g} / \mathrm{km}]$ de . $[1,17]$

\section{CONCLUSÃO}

Tanto a análise teórica de ensaios de veículos leves realizados com gasolina, suas misturas com etanol, GNV ou diesel, como a análise dos resultados das emissões de , de cerca de 900 ensaios de veículos flex homologados entre 2010 e 2011 utilizando gasool A22 de referência, comprovam que não há mudanças significativas 
nos resultados das grandezas relacionadas aos NMHC, pois os valores de $\mathrm{Fr}_{\mathrm{CH}_{4}}$, são muito próximos do valor da constante $\mathrm{R}$ definida neste trabalho.

As grandezas associadas ao grupo de componentes (NMHC - ETOH) sofrem mudanças significativas quando se compara a metodologia descrita pela Ata da $88^{\text {a }}$ Reunião da Comissão Técnica de Acreditação de Laboratórios de Emissões e a metodologia da norma ABNT NBR 6601:2012, não sendo proporcional ao valor do $\mathrm{Fr}_{\mathrm{CH}_{4}}$, apesar dos dois métodos utilizarem o desconto por concentração.

Independente do fator de resposta empregado, estes são intrínsecos a cada aparelho e devem ser determinados e verificados periodicamente, como por ocasião da calibração de rotina do analisador DIC.

Como há inúmeras variáveis que afetam os fatores de resposta discutidos, é incorreto afirmar que bancadas que apresentem valores altos de $\mathrm{Fr}_{\mathrm{CH}_{4}}$ e $\mathrm{Fr}_{\mathrm{ETOH}}$ em relação a outras gerarão resultados menores de $\mathrm{NMHC}_{\mathrm{MP}}$ e/ou $(\mathrm{NMHC}-\mathrm{ETOH})_{\mathrm{MP}}$. Portanto, não se deve utilizar de comparação isolada de valores de fatores de resposta do DIC como estratégia de vantagem comercial entre os LEV.

Apesar da atual metodologia de cálculo de (NMHC - ETOH) presente na norma ABNT NBR 6601:2012 utilizar o conceito do $\mathrm{Fr}_{\mathrm{CH}_{4}}$, incluindo uma correção necessária em termos de conceito, essa alteração não foi expandida aos limites máximos estabelecidos pelo PROCONVE para veículos leves. Houve alteração de metodologia de cálculo, porém os limites vinculados a esta não foram objeto de discussão.

Os resultados aqui apresentados mostram que a alteração na metodologia de cálculo de hidrocarbonetos não metano descontado o etanol, válida desde 18 de outubro de 2012, para veículos leves alimentados com etanol hidratado gerou benefício em termos de limites alvo máximos, ou seja, um mesmo ensaio gera resultados menores de $(\mathrm{NMHC}-\mathrm{ETOH})_{\mathrm{MP}}$ quando comparado à metodologia empregada anteriormente a data citada, para um mesmo limite máximo de emissão.

Tal abordagem é prejudicial ao meio ambiente e à indústria automobilística, sendo necessárias discussões em termos de rever os limites de $(\mathrm{NMHC}-\mathrm{ETOH})_{\mathrm{MP}}$ de veículos leves do PROCONVE abastecidos com etanol hidratado, com o intuito de reduzi-los (a última alteração nos limites máximos de NMHC em veículos leves ocorreu na transição das fases L4 para L5 do PROCONVE, que está em vigência desde 01 de janeiro de 2009, e a nova fase L6 não possui mudanças para este poluente).

Pelo trabalhado desenvolvido neste artigo, embasado em uma ampla abordagem e com um vasto conjunto de dados, sugere-se, o mais breve possível, a atualização dos atuais limites máximos de emissão de $\mathrm{NMHC}_{\mathrm{MP}}$ para veículos leves ensaiados com gasolina, etanol e suas misturas, independente da fase do PROCONVE, sem prejuízo para qualquer parte interessada, conforme indicado pela Tabela 03.

\section{REFERÊNCIAS}

[1] Norma ABNT NBR 6601:2012 - Veículos rodoviários automotores leves Determinação de hidrocarbonetos, monóxido de carbono, óxidos de nitrogênio, dióxido de carbono e material particulado no gás de escapamento; 
[2] Linke, R. R. A.; Branco, M. G.; Conti, E. W.. Considerações sobre a medição da emissão evaporativa em veículos a álcool. São Paulo: SIMEA, 1989.

[3] Instituto Brasileiro do Meio Ambiente e dos Recursos Naturais Renováveis. Programa de Controle da Poluição do Ar por Veículos Automotores PROCONVE/PROMOT/IBAMA - Coleção Meio Ambiente, Série Diretrizes - Gestão Ambiental, $n^{\circ} 3,3^{\mathrm{a}}$ ed., Brasília: IBAMA/DIQUA, 2011, pag. 15.

[4] Portaria ${ }^{\circ}$ 346, de 19 de novembro de 1976, do Ministério da Indústria e Comércio;

[5] Portaria $\mathrm{n}^{\circ}$ 16, de 29 de julho de 1993, do Departamento Nacional de Combustíveis, do Ministério de Minas e Energia;

[6] Portaria $\mathrm{n}^{\circ} 23$, de 06 de junho de 1994, do Departamento Nacional de Combustíveis, do Ministério de Minas e Energia;

[7] Resolução CONAMA n ${ }^{\circ}$ 03/1989 - Dispõe sobre níveis de Emissão de aldeídos no gás e escapamento de veículos automotores. D.O.U. de 25.08.1989;

[8] Resolução CONAMA n ${ }^{\circ} 15 / 1989$ - Dispõe sobre apresentação de EIAS, pela PETROBRÁS, sobre o uso de etanol como combustível. D.O.U. de 24.01.1990;

[9] Resolução CONAMA n 09/1994 - Estabelece prazo para os fabricantes de veículos automotores leves e equipados com motor a álcool declararem ao IBAMA e aos órgãos ambientais técnicos designados os valores típicos de emissão de hidrocarbonetos, diferenciando os aldeídos e os álcoois, em todas as suas configurações de produção. D.O.U. de 04.10.1994. Cumpriu seu objeto;

[10] Associação Nacional de Fabricantes de Veículos Automotores (ANFAVEA). Anuário da Indústria Automobilística Brasileira - 2012, São Paulo: FSC, 2012.

[11] Norma ABNT NBR 6601:2005 - Veículos rodoviários automotores leves Determinação de hidrocarbonetos, monóxido de carbono, óxidos de nitrogênio, dióxido de carbono e material particulado no gás de escapamento;

[12] Resolução CONAMA n ${ }^{\circ}$ 418/2009 - Dispõe sobre critérios para a elaboração de Planos de Controle de Poluição Veicular (PCPV) e para a implantação de Programas de Inspeção e Manutenção de Veículos em Uso - I/M pelos órgãos estaduais e municipais de meio ambiente e determina novos limites de emissão e procedimentos para a avaliação do estado de manutenção de veículos em uso. D.O.U. de 26.11.2009;

[13] Norma ABNT NBR 8689:2012 - Veículos rodoviários leves - Combustíveis para ensaio - Requisitos;

[14] Instrução Normativa IBAMA n ${ }^{\circ}$ 54/2004 - Regulamenta a medição do NMHC. D.O.U. de 22.11.2004;

[15] Comissão Técnica de Acreditação de Laboratórios de Emissões. Ata da $88^{a}$ Reunião da Comissão Técnica de Acreditação de Laboratórios de Emissões 07.12.2006;

[16] Comissão Técnica de Acreditação de Laboratórios de Emissões. Lista de presença da $88^{a}$ Reunião da Comissão Técnica de Acreditação de Laboratórios de Emissões 07.12.2006;

[17] Dados levantados pela Companhia Ambiental do Estado de São Paulo, CETESB, dos relatórios de ensaios dos processos de homologação de veículos leves de passageiros flex referentes ao período de 2010 e 2011 e dados de análise crítica. 